\title{
Spatial Disparities in Air Conditioning Ownership in Florida, United States
}

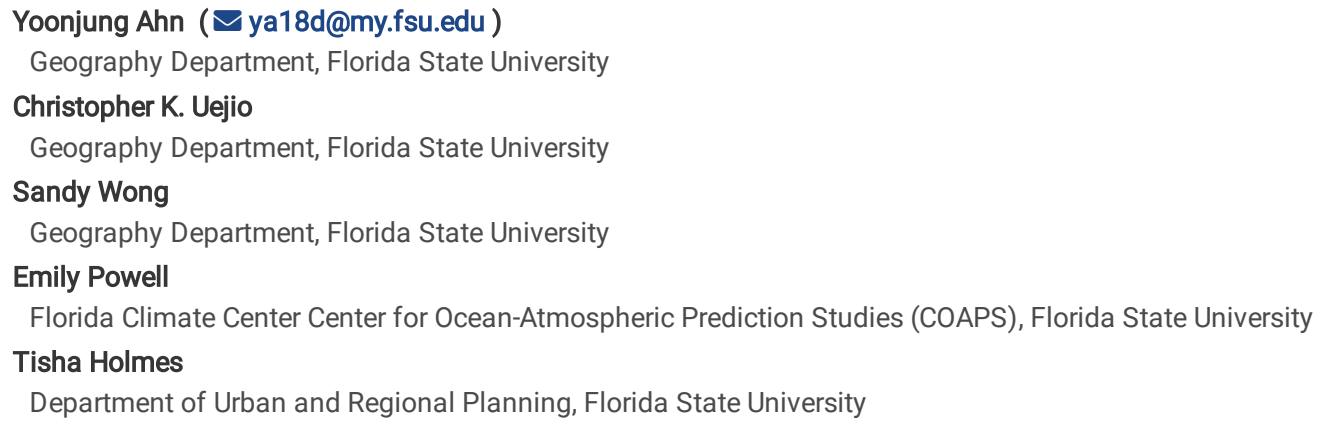

\section{Research Article}

Keywords: indoor environment, housing environment, heat exposure, heat-related illnesses, cooling system

Posted Date: February 8th, 2022

DOI: https://doi.org/10.21203/rs.3.rs-1321547/v1

License: () (7) This work is licensed under a Creative Commons Attribution 4.0 International License. Read Full License 


\section{Abstract}

\section{Background}

Air conditioning usage is the most effective intervention to prevent heat-related illnesses such as heat exhaustion and heatstroke. However, limited geographic coverage and outdated information on air conditioning (AC) availability limit extreme heat risk mapping and prevention efforts.

\section{Methods}

This paper contributes to this research gap by using updated AC availability data to detect areas in Florida, U.S., with significant AC needs and to assess the factors associated with AC ownership. Leveraging property databases, this study first identified Florida, U.S. census tracts by applying Moran's I and Local Indicators of Spatial Association (LISA) and applied Spatial Durbin Model (SDM) to investigate the relationship between AC ownership and sociodemographic characteristics.

\section{Results}

Clusters of significantly high and low values $(p<0.05)$ of AC ownership were found across Florida. High-high clusters of AC ownership were found in the northern and eastern coasts, including large metropolitan areas such as Jacksonville, Sarasota, Fort Lauderdale, and Daytona Beach. Clusters with no AC were located in the interior of Florida. We closely looked at AC prevalence clusters in Duval County which contains the city of Jacksonville. Clusters of households with low to no AC availability were found in the urban core, where there is high poverty, poor housing conditions, and low education levels. SDM results showed a significant association between AC ownership and socioeconomic and urbanicity (urban and rural) variables. In particular, we found that a higher proportion of households without an AC are located in predominantly Black or African American neighborhoods, indicating racial disparities in AC ownership.

\section{Conclusions}

Our results can be used to target neighborhoods that are in great need of heat prevention measures. For instance, part of the Low-Income Home Energy Assistance Program offers financial assistance to families with low incomes for energy bills initiated to provide AC units. The result of this study can be used to support this policy.

\section{Trial registration}

Not applicable

\section{Background}

Extreme heat exposure can cause heat-related illness and exacerbations of respiratory, cardiovascular, and renal disease [1]. Disparities of heat exposures and sensitivities exist according to an individual's environmental conditions and social and economic position [2-4]. Key heat risk groups include the elderly, the poor, people with pre-existing health conditions, or high heat exposure [3]. Buildings with inadequate climate controls and neighborhoods with less greenspace also face elevated heat exposures [3-6].

A significant number of studies investigated the association of outdoor air temperature and socioeconomic and environmental variables [7, 8]. However, the a greater risk to vulnerable people in indoor environments [9-12]. Therefore, a large and growing body of literature investigated the relationship between heat exposure in indoor environments. More specifically, many studies focused on the temperature difference between the indoors and outdoors according to air conditioning (AC) availability [13-15]. According to AC ownership, Waugh et al. (2021) found that daily mean indoor air temperature varies from $10{ }^{\circ} \mathrm{C}$ lower to $10{ }^{\circ} \mathrm{C}$ higher than the outdoor temperature. Quinn et al. (2017) discovered indoor temperatures are highly associated with cooling system types. Furthermore, studies have linked AC ownerships to rates of heat-related health effects. Semenza et al. (1996), Ostro, Rauch, Green, Malig, \& Basu (2010), Cardoza et al. (2020), and O'Neill, Zanobetti, \& Schwartz (2005) confirmed a negative relationship between mortality rates and AC ownership.

The 1980 US Decennial Census was the last nationwide survey to examine neighborhood-level central AC prevalence across the US Thus, studies applying heat mapping methods to identify disparities and target health interventions have been hampered by limited AC prevalence information [5, 20-22]. Outdated information on AC prevalence constrains the optimal targeting of interventions such as cooling refuges, energy subsidies, and free AC distribution.

A few studies incorporated AC information from the US Census Bureau's American Housing Survey (AHS) into census tract-level data. However, the data from AHS is only available at the county level for select metropolitan areas. Gronlund \& Berrocal (2020) applied American Housing Survey microdata and estimated $\mathrm{AC}$ availability at the parcel level, but the accuracy varied between cities and did not account for the spatial heterogeneity of AC prevalence.

In the absence of a nationwide census, real estate companies, which collect high-quality property information, could provide reliable AC prevalence information. The present study partnered with 'Estated,' a private real estate company, to identify areas with the most significant AC needs and prioritize implementing heat prevention measures. To achieve the goal, we applied Local Indicators of Spatial Association (LISA) to research spatial clusters of AC prevalence in Florida and investigate the relationship between AC ownership and socioeconomic variables.

\section{Methodology}

\subsection{Study site}


Hotter and more humid air masses influence subtropical and tropical climate areas more than other climates [24]. In these areas, indoor environments without an adequate cooling system can cause indoor overheating [25]. In Florida, statewide average temperatures are higher than 30 degrees Celsius during the summer, and some residents lack AC units to manage cool indoor environments. According to the AHS, in 1980, $15.66 \%$ of Florida households had no AC, $54.79 \%$ of households had central AC, $17 \%$ of one individual room unit, and $10.27 \%$ of houses had two or more individual room units. Therefore, this study investigated residential AC availability at the census tract level in Florida from the historical records up through 2019 using a novel real estate dataset to reflect more current/updated estimates of $\mathrm{AC}$ saturation.

We further assessed the patterns of AC ownership within Duval County (Jacksonville). Duval is rapidly growing and contains metropolitan (Jacksonville) as well as urban, suburban and rural areas (Figure 1). During the Florida land boom in the 1920s, Jacksonville was considered a "Gateway to Florida" [26]. Jacksonville's population tripled between 1950 to 2000 [27], and the city hosts 949,611 residents as of 2020, making it the 13th most populous city in the US. and the fourth largest metropolitan city in Florida. Jacksonville has the continental US's largest city area $\left(747 \mathrm{mi}^{2}\right)$.

According to American Community Survey (ACS) 2019, the racial composition of Jacksonville was White 58.22\%, Black or African American 30.95\%, Asian $4.76 \%$, two or more races $3.64 \%$.

To increase understanding of Duval County's general socioeconomic characteristics, our analysis was conducted within Duval County Health Department Health Zones (HZ). In 2015, HZ grouped zip codes with similar economic, educational, geographic, political, and social boundaries (Yu, 2016). For instance, according to ACS estimates census tract 2014, HZ1 is the most populated urban area, and more than $80 \%$ of the residents are African American. $\mathrm{HZ} 5$ is considered to be the most rural area, while $\mathrm{HZ} 3$ and $\mathrm{HZ} 6$ contain less than $20 \%$ African Americans. Hispanic residents are primarily located in $\mathrm{HZ2}$ (41\%), $\mathrm{HZ} 4$ (23\%), HZ3 (19\%) in Duval County. HZ1 showed large health disparities in many indicators such as low income, low education, and high unemployment rates compared with the other $\mathrm{HZs}$ [28].

\subsection{Data}

\subsubsection{Property data}

'Estated,' which has access to more than 150 million properties nationwide, provided housing information. The dataset includes detailed information on individual properties, including building structure, market value, taxes and assessment, and historical deeds. Estated provided information on $72,954,014$ residential properties in Florida. We excluded the properties that were missing either the year of construction or AC types which left 42,679,440 properties for the analysis. Lafayette County, Liberty County, Miami-Dade County, Polk County, and Leon County were the top 5 counties that had the most missing data of AC ownership (Appendix).

\subsubsection{Contemporary and historical socioeconomic variables}

\subsubsection{Contemporary socioeconomic variables}

Intuitively, AC ownership is related to residents' socioeconomic position. Biddle (2008) investigated the growth of AC prevalence with historical census data and showed that AC ownership doubled up in the 1980s compared to the 1960s due to the development of affordable AC units, declining cost of electricity, increasing household incomes, and new housing developments. Several studies found that residential building characteristics were related to AC ownership $[19,23,29,30]$ such as year built showed a positive relationship with AC prevalence and [21] the value of the property, and total square ft of property showed a negative relationship with AC ownerships [31]. We referred to the study mentioned above and collected ten variables from 5 year ACS (2019) at the census tract level. In Florida, this sample includes approximately 3.54 million housing units (Table 1).

\subsubsection{Historic sociodemographic variables}

Recent studies argue that redlining, or historic disinvestment in neighborhoods with historically high proportions of foreign-born populations, are related to contemporary health inequalities [32,33]. Historical development and neighborhood characteristics may also influence building amenities such as AC availability [34]. Since historic redlining information is only available for three cities in Florida, we included census tract-level Black/African American population from the US 1970 decennial census [35]. This date follows the passage of the 1968 Fair Housing Act and likely contains vestiges of past discriminatory practices.

\subsubsection{Urbanicity variable}

The United States Department of Agriculture (USDA) (2010) classifies census tracts into 11 urban and rural subtypes based on population density, urbanization, and commuting patterns. The study collapsed the ten original urban/rural codes into four classes: Metro Urbanized Areas (UAs) (Metropolitan area core UA, Metropolitan area high commuting UA, Metropolitan area low commuting UA), Metro Urban Clusters (UCs (Micropolitan area core large UC, Micropolitan high commuting large UC, Micropolitan low commuting large UC), Town UC (Small-town core small UC, Small-town high commuting small UC, Small-town low commuting small UC), and Rural (outside a UA or UC) (Table 1). 
Table 1

Variable categories and data sources

\begin{tabular}{|c|c|c|c|}
\hline Category & Variables & Sub-Categories & Data Source \\
\hline \multirow[t]{4}{*}{ Property } & Built year & - & Estated (2021) \\
\hline & Air conditioning types & $\begin{array}{l}\text { None, Central, } \\
\text { Other }\end{array}$ & Estated (2021) \\
\hline & Value & - & United States Census Bureau (2019) \\
\hline & $\begin{array}{l}\text { The average number of rooms per } \\
\text { residence }\end{array}$ & & United States Census Bureau (2019) \\
\hline \multirow{6}{*}{$\begin{array}{l}\text { Contemporary } \\
\text { sociodemographic }\end{array}$} & $\% 65$ and over, lives alone & - & United States Census Bureau (2019) \\
\hline & $\begin{array}{l}\% \text { Households with complete plumbing } \\
\text { facilities }\end{array}$ & & United States Census Bureau (2019) \\
\hline & $\%$ Renter occupied & - & United States Census Bureau (2019) \\
\hline & $\%$ Black or African American & - & United States Census Bureau (2019) \\
\hline & $\%$ Hispanic or Latino & - & United States Census Bureau (2019) \\
\hline & Median household income & - & United States Census Bureau (2019) \\
\hline Historic demographic & $\%$ Black or African American & - & IPUMS NHGIS, (1970) \\
\hline Urbanicity & Urban and rural codes & $\begin{array}{l}\text { 1. Metro_UA } \\
\text { 2.Metro_UC } \\
\text { 3.Town_UC } \\
\text { 99: Not coded }\end{array}$ & $\begin{array}{l}\text { United States Department of Agriculture (USDA) } \\
\text { (2013) }\end{array}$ \\
\hline
\end{tabular}

\subsubsection{Data preprocessing}

We extracted built year, total property square footage, and AC types from the Estated dataset and aggregated the AC dataset to the census tract level. The Estated dataset provided individual properties' AC type information such as central, chilled water, evaporative cooler, geothermal, packaged AC unit, partial, refrigeration, ventilation, wall unit, window unit, yes, none, and others. Some studies differentiated cooling effectiveness among various AC types (Quinn, Kinney, \& Shaman, 2017; Waugh et al., 2021). Waugh et al. (2021) found that houses with room AC units had an average of 2 degrees Celsius higher indoor temperature than houses with central AC. Quinn et al. (2017) suggested portable AC was closer to not having an AC than central AC based on room temperature.

Some jurisdictions only reported the presence or absence of AC which constrained the statewide analysis of residential AC types. Thus, the study grouped AC into three categories: any AC (packaged AC unit, chilled water, geothermal, commercial unit, central AC, wall unit, window unit, evaporative cooler, and other AC unit), no AC (none and ventilation), and missing data. The study did presume that areas with $100 \%$ of any AC automatically had no households without AC since there were residences with missing $A C$ information across the study area. Next, we calculated the percentage of each $A C$ type at the census tract level by dividing it by the total number of units reporting AC availability.

We calculated the \% of renter-occupied and \% households with complete plumbing facilities divided by the number of total housing units. After that, we merged the Estated data with socioeconomic variables data we gathered from ACS with census tract based on the Federal Information Processing Standards code. The contemporary socioeconomic variables were converted to proportion of the population (Table 1). We calculated \% Black or African American from the historic total population Black or African American and matched it with the contemporary census tract.

To compare the effect of each variable on the dependent variable, we standardized all variables by converting them to Z-scores (subtracting the mean and dividing by the standard deviation). We standardized to avoid over-emphasizing one variable's effect on the dependent variable.

\subsection{Statistical analysis}

This analysis aimed to identify the spatial autocorrelation of AC availability in Florida. We separately applied Moran's I test to the percentage of anyAC or noAC with the 'spdep' package in R [39] to examine spatial autocorrelation in Florida. Moran's I statistic is a global spatial autocorrelation statistic designed to test the null hypothesis of complete spatial randomness. To conduct the Moran's I statistic test, we defined the neighborhood of census tract polygons with the queen criterion of contiguity. We applied a binary weights matrix without row standardization, which gives more weight to areas with more neighbors.

Among the total of 4,152 census tracts from 67 counties, some census tracts contained missing values. Therefore, we included 1,172 census tracts from 26 counties for any AC and 1,166 census tracts from 23 counties for the no AC analysis. Based on the available data, the Duval County analysis examined a 
different number of any AC census tracts (173) versus the no AC analysis (134). Due to missing data, the study did not presume neighborhoods with $100 \%$ AC saturation imply no households with $\mathrm{AC}$ does not infer that only having any $\mathrm{AC}$ records means $0 \%$ no $\mathrm{AC}$

We applied Local Indicators of Spatial Association (LISA) to AC availability in Florida with the 'spdep' package in R version 4.1.1 [39] at the census tract level. We operationalized neighborhoods using queen contiguity without row standardization to conduct LISA analysis. The sub-analysis reports specific information for Duval County.

Next, we fit a regression model to analyze the relationship between AC availability and socioeconomic variables in Florida. To consider potential multicollinearity between independent variables, we retained explanatory variables when the Variance Inflation (VIF) was less than 5. The percentage of households without AC was the dependent variable, and the rest were independent variables (Table 1).

Spatial regression models, including spatial error (SEM) and spatial lag model (SLM), are commonly applied to handle residual autocorrelation [5]. The spatial lag model (SLM) can be used for a diffusion process that looks at how one event increases the likelihood of similar events in neighborhood areas [40]. SEM treats spatial dependence as a nuisance, which means SEM removes the autocorrelation by adding a spatial correlation term to the residuals [41]. However, some studies suggested that applying either SEM or SLM can lead to erroneous conclusions[42, 43]. For example, the SLM model cannot account for spatial correlation in the error term, and SEM cannot provide information about indirect effects of neighbors [43]. To capture both error dependence and spatially lagged dependence, we applied the Spatial Durbin Model (SDM) [43,44]. The SDM is considered more robust since it considers both local and global spatial effects with no prior restrictions on the magnitude of potential direct and indirect effects [42].

SDM provides direct effect and indirect independent variable effect estimates. The direct effect refers to the changes of dependent variable effects on a census tract, and this also considers how the census tract changes affect its neighbor census tract [45]. Indirect effect or spatial spillover effect refers to the neighboring dependent variable's impact on their census tracts' dependent variable, while the total effect sums the direct and indirect effects [45]. The results report the standardized beta coefficients (one standard deviation change), 95\% confidence intervals, and p-values.

\section{Results}

\subsection{Descriptive statistics}

AC ownership summary is described in Table 2. According to the summary, 31,261,448 (74\%) of houses have central AC, $10,246,944$ ( $24 \%)$ of houses indicated Yes to $A C, 21,922(1 \%)$ of houses have other types of $A C$, and $700,649(1 \%)$ of households had no AC.

Table 2

summary of AC ownership in Florida

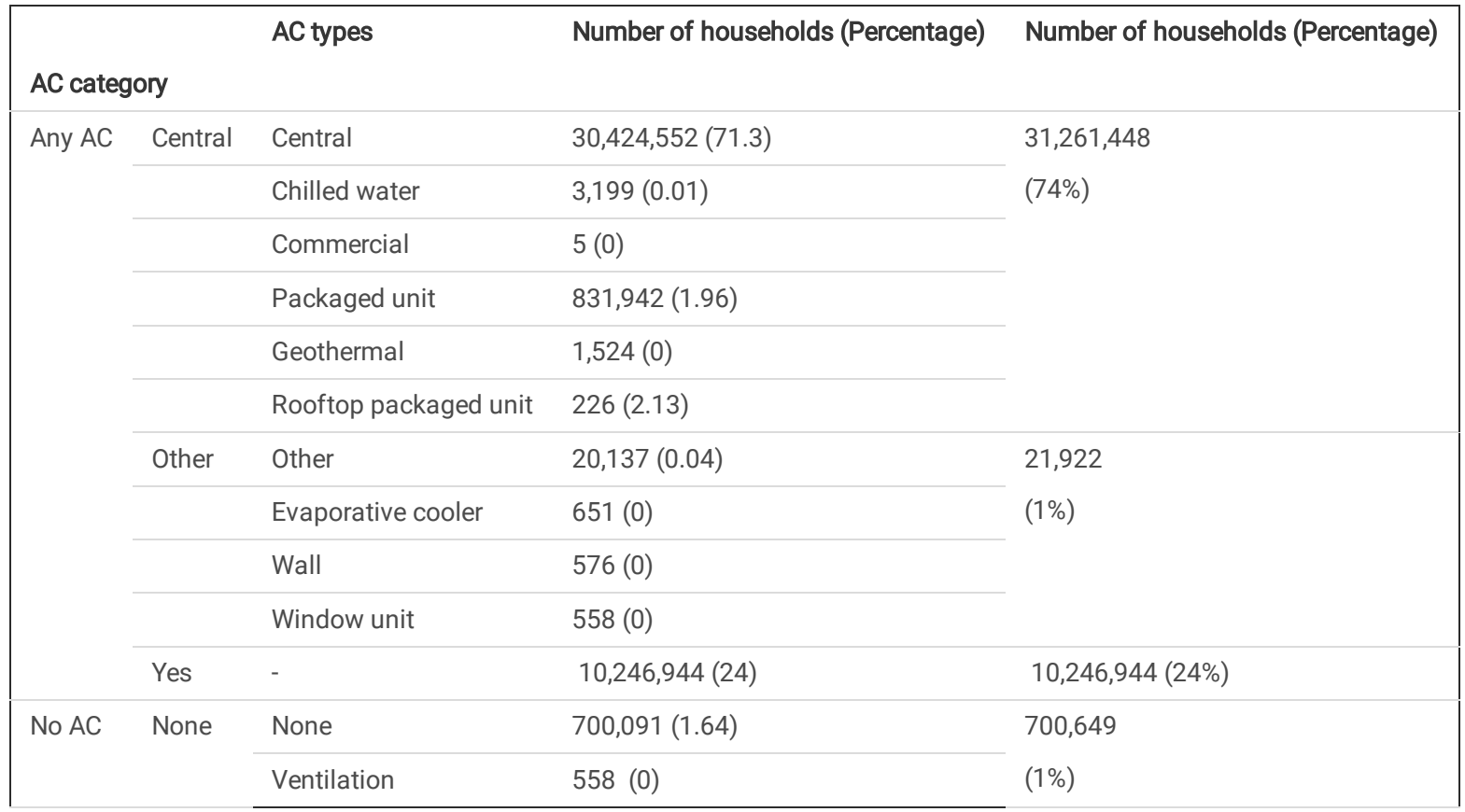

Figure 2-a illustrates the percentage of any AC at the county level in Florida. Most counties had more than 75\% of AC ownership (Figure 2-a). Among the 58 counties with sufficient data, eight counties had $100 \%$ any AC (either Central, Other, or Yes) prevalence. There were some counties with a high percentage of no AC, including Monroe County (23\%), Hamilton County (21\%), Franklin County (16\%), Bradford County (13\%), Okeechobee County (13\%), and Hendry County (10\%) (Figure 2-b). 


\subsection{Spatial clusters in Florida}

We conducted spatial autocorrelation analysis to identify the areas with high and low AC prevalence at the census tract level. Moran's I statistics and the LISA maps (Figure 3) confirmed the spatial autocorrelation of AC availability. Any type of AC exhibited strong and statistically significant spatial autocorrelation (Moran's I 0.64, p-value < 0.05). Out of 1,062 census tracts, 184 census tracts $(17.3 \%)$ were in a high AC prevalence neighborhood geographically adjacent to another high prevalence area $(\mathrm{p}<0.05)$. The counties with the highest percentage of neighboring high-high census tracts include $49.5 \%$ in Duval County, $17 \%$ in Broward County, and 11\% in Volusia County. Two hundred and three census tracts (19\%) out of 1,062 census tracts were low-low, indicating significant ( $p$ < 0.05) clustering in 5 counties: $40 \%$ of the low-low census tracts in Duval County, 26 \% in Hillsborough County, and 20 \% in Sarasota County (Figure 3-a).

No AC census tracts also showed statistically significant spatial autocorrelation (Moran's I statistic 0.73 , p-value $<0.05$ ). One hundred seventy-four out of 1167 (15\%) census tracts were contained within high-high no central AC clusters across six counties. Fifty percent of these clusters were found in Pinellas County, 29\% in Palm Beach County, and 20\% in Volusia County (Figure 3-b).

To take a closer look at the spatial clusters, we visualized the LISA clusters for central AC and no AC in Duval County in Florida (Figure 4). Figure 4-a shows $11 \%$ of census tracts were found in high-high anyAC clusters, and $5 \%$ of census tracts ( 9 census tracts out of 170 ) were in low-low clusters. $\mathrm{HZ} 1$ contained nine census low-low cluster tracts. We also investigated the spatial clusters of no AC availability (Figure 4-b), which were reported from fewer neighborhoods. Twelve census tracts out of 134 were located in high-high clusters of no AC, which were primarily located within HZs 1 and 5 .

\subsection{Relationship between AC availability and socioeconomic variables}

Several socioeconomic variables showed statistical significance associated with the percentage of no AC. Table 3 reports the effect with three matrices: direct, indirect, and total. We discovered that \% Black or African American showed a positive relationship with lack of AC ownership in direct (0.01, 95\% Cl:0.00,0.01), and total effects $(0.01,95 \% \mathrm{Cl}: 0.01,0.02)$. People living in historically Black or African American (1970 Census) areas with lower housing quality were also less likely to have any type of $\mathrm{AC}$ : direct $(0.01,95 \% \mathrm{Cl}: 0.00,0.01)$ and indirect effect $(0.00,95 \% \mathrm{Cl}:-0.01,0.00)$. The percentage of households without $\mathrm{AC}$ and median household income showed a significant indirect effect $(-0.01,95 \% \mathrm{Cl}:-0.01,0.00)$. Renters were also less likely to have AC, with a significant indirect effect (0, 95\% Cl: 0.00, 0.01).

Many of the residential property features were significantly associated with no AC. The average number of rooms per residence was negatively related with a percentage of households without AC across all effect categories: direct impact $(-0.01,95 \% \mathrm{Cl}:(-0.01,0.00)$, indirect $(-0.01,95 \% \mathrm{Cl}$ : $-0.01,0.00)$, and total impact $(-0.02,95 \% \mathrm{Cl}:-0.02,-0.01)$. Older houses tend not to have any AC units. The built year was also negatively associated with the percentage of households without AC in direct effect (-0.01, 95\% Cl:-0.02,-0.01) and total effect (-0.02, 95\% Cl:-0.02,-0.01). Metro Clusters showed a statistically significant effect: direct effect $0.15(95 \% \mathrm{Cl}: 0.11,0.19)$ and total effect $0.15(95 \% \mathrm{Cl}: 0.10: 0.20)$ with the percentage of property without AC. Rural Clusters also showed the largest effect of all the variables, including in direct $(0.29,95 \% \mathrm{Cl}: 0.25,0.34)$, indirect $(0.04,95 \% \mathrm{Cl}: 0.01,0.07)$, and total effect $(0.33,95 \% \mathrm{Cl}$ : $0.29,0.38)(\mathrm{Table} 3)$.

Table 3

Beta coefficient with $95 \%$ confidence intervals from Spatial Durbin Model 


\begin{tabular}{|c|c|c|c|}
\hline Variables & $\begin{array}{l}\text { Direct } \\
\text { (95\% confidence interval) }\end{array}$ & $\begin{array}{l}\text { Indirect } \\
\text { (95\% confidence interval) }\end{array}$ & $\begin{array}{l}\text { Total } \\
\text { (95\% confidence interval) }\end{array}$ \\
\hline \multirow[t]{2}{*}{ Built Year } & $-0.01 * \star \star(-0.02,-0.01)$ & 0.00 & $-0.02^{\star \star \star}$ \\
\hline & & $(-0.01,0.01)$ & $(-0.02,-0.01)$ \\
\hline \multirow[t]{2}{*}{ Total area of property } & $-0.06^{\star \star \star}$ & 0.00 & $-0.06 * \star \star$ \\
\hline & $(-0.10,-0.02)$ & $(0.00,0.01)$ & $(-0.10,-0.03)$ \\
\hline \multirow[t]{2}{*}{ Urbanicity (Metro UC) } & $0.15^{\star \star \star}$ & 0.00 & $0.15^{\star \star \star}$ \\
\hline & $(0.11,019)$ & $(-0.02,0.02)$ & $(0.10,0.20)$ \\
\hline \multirow[t]{2}{*}{ Urbanicity (Rural) } & 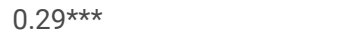 & $0.04 * \star$ & $0.33^{\star \star \star}$ \\
\hline & $(0.25,0.34)$ & $(0.01,0.07)$ & $(0.29,0.38)$ \\
\hline \multirow[t]{2}{*}{ Over 65 years old } & 0.00 & $0.09 * \star \star$ & $0.09 \star \star \star$ \\
\hline & $(0.00,0.01)$ & $(0.04,0.14)$ & $(0.04,0.14)$ \\
\hline \multirow[t]{2}{*}{ Black or African American } & $0.01^{\star \star *}$ & 0.00 & $0.01^{\star \star}$ \\
\hline & $(0.00,0.01)$ & $(-0.01,0.01)$ & $(0.00,0.02)$ \\
\hline \multirow[t]{2}{*}{ Renter Occupied } & 0.00 & $0.00 * \star \star$ & 0.00 \\
\hline & $(-0.01,0.00)$ & $(0.00,0.01)$ & $(-0.01,0.01)$ \\
\hline \multirow[t]{2}{*}{ Median Household Income } & 0.00 & $-0.01 * \star \star$ & 0.00 \\
\hline & $(-0.01,0.01)$ & $(-0.01,0.00)$ & $(-0.01,0.01)$ \\
\hline \multirow[t]{2}{*}{ Hispanic or Latino } & 0.00 & -0.01 & 0.00 \\
\hline & $(-0.01,0.01)$ & $(-0.01,0.00)$ & $(-0.01,0.01)$ \\
\hline \multirow[t]{2}{*}{ Property Value } & 0.00 & $-0.01 * \star \star$ & -0.01 ** \\
\hline & $(-0.01,0.00)$ & $(-0.01,0.00)$ & $(-0.01,0.00)$ \\
\hline \multirow[t]{2}{*}{ Number of rooms } & $-0.01 * \star \star$ & $-0.01 * \star$ & $-0.01 * \star \star$ \\
\hline & $(-0.01,0.00)$ & $(-0.01,0.00)$ & $(-0.02,-0.01)$ \\
\hline \multirow[t]{2}{*}{ Historically Black or African American } & $0.01^{\star \star \star}$ & $0.00 * \star \star$ & 0.00 \\
\hline & $(0.00,0.01)$ & $(-0.01,0.00)$ & $(0.00,0.01)$ \\
\hline \multirow[t]{2}{*}{ Complete plumbing } & $0.00 * \star \star(-0.01,0.00)$ & 0.00 & $0.00 \star *$ \\
\hline & & $(-0.01,0.00)$ & $(-0.01,0.00)$ \\
\hline \multicolumn{4}{|l|}{ * significant at $90 \%$ intervals } \\
\hline \multicolumn{4}{|l|}{ ** significant at $95 \%$ intervals } \\
\hline 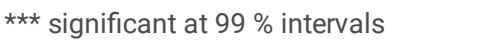 & & & \\
\hline
\end{tabular}

\section{Discussion}

The result of the LISA analysis illustrates a significant number of spatial clusters of AC ownerships in Florida that can be used to provide resources for heat prevention, such as supplying AC units, installing cooling centers, and distributing energy subsidies. This study found clusters of households without any AC in interior in Duval, Escambia, Hillsborough, Pinellas, and Sarasota. We also investigated spatial clusters in Duval County and found overlaps between low-low of any AC ownership in HZ1 (Figure 4). HZ1 represents the urban core and has the greatest portion of people living in poverty, poor housing conditions, and the highest proportion of residents who receive federally assisted subsidized housing. Shorstein et al. (2017) conducted a health impact assessment of Subsidized Housing in Duval County and found HZ1 has a high proportion of poverty, poor housing conditions, and heat-sensitive pre-existing medical conditions (Eastside Environmental Council 2021). These results illustrate that AC ownership is likely to be associated with socioeconomic variables, health outcomes, and the AC availability can be considerably varied within a state and a county[19, 23, 29, 30].

We applied a SDM to investigate the association between socioeconomic, urbanicity, and AC prevalence. The results align with previous studies where Black households had lower rates of central AC ownership [39]. O'Neill et al. (2005) investigated AC ownership and mortality rate by race in four cities in the Midwest, US, and found that Black households had half the central AC prevalence as White households. The present study confirmed lower magnitude AC access disparities by race, income, and geographic location. This study confirms earlier findings that some socioeconomic variables such as median household income and $\% 65$ or older living alone showed significant association with the lack of AC prevalence [9, 46, 47]. We also considered property variables that may be associated with AC prevalence. The mean of the built year of property showed the third-highest effect with the percentage of 
households without AC. This result aligns with previous research which developed AC estimation models with the American Housing Survey data. Gronlund and Berrocal (2020) discovered that the built year showed a positive relationship with AC ownership and was a strong predictor.

Among all the variables, Rural Clusters showed the strongest relationship with the percentage of properties without AC. Kovach, Konrad, \& Fuhrmann (2015) found more Emergency Department visits from rural areas than urban areas in North Carolina in the US, and they tended to be elderly, socially isolated, noncitizens, agricultural laborers who cannot avoid the heat, and mobile home residents. Metro Clusters had the second strongest positive relationship with the percentage of properties without AC. We believe that this association reflects Florida's urban development history. Urban core areas tend to have older apartments and houses [49]. The Federal Housing Administration refused to pay for AC renovations from inner urban houses, areas with low home values, and a high ratio of foreign-born residents [32, 50]. "White flight," or the migration of Anglo Americans from urban areas to the suburbs after the passage of the Fair Housing Act of 1968, contributed to lower capital investment and urban housing quality.

To minimize overall health risks associated with heat, policies, and programs such as Housing Energy Assistance Program and Low Income Home Energy Assistance Program (LIHEAP) should target neighborhoods with low AC prevalence and/or lower socioeconomic position (Fraser et al., 2017). Moreover, jurisdictions should consider supporting the installation of central AC since other types of AC such as a wall, window, and portable AC are not as effective at mitigating heat-related symptoms and illness $[13,15]$. We will need to consider providing subsidies for installing central AC, electricity bills, or improving housing conditions. Increasing green space and designating cooling centers in neighborhoods with less AC prevalence could also be another option.

This study has illustrated several strengths of utilizing real estate data to analyze disparities of AC ownership in Florida. However, there are a few limitations should be addressed. There are limitations of estimating housing characteristics from historical property records. This study aggregated all types of AC due to non-standardized AC reporting practices. For example, some jurisdictions only indicated AC ownership as 'yes' instead of reporting a specific type of AC. Moreover, how AC information is coded is unclear. AC type recorded as no AC can be not available or not having any AC. However, a few studies showed that wall, window, or portable unit $A C$ are not as effective as central $A C[13,15,18]$. Moreover, this database did not report the exact dates when housing information was updated and may miss recent improvements that are not reflected in the dataset. Nationwide AC ownership information should be gathered in the future, and it will benefit researchers and governmental decision-makers. In addition, we recognize the limitation of the spatial scale of socioeconomic variables. We applied aggregated sociodemographic information at the census tract level.

To address this study's limitations, future research should collect fine-scale data that will produce more actionable results for urban planners, housing advocates, and public health officials [20]. Utilizing AC has been shown to significantly reduce heat-related mortality rates and illnesses, which is an important public health concern $[19,51,52]$. Therefore, there is a need to develop new AC technologies that have less of a carbon footprint and better energy efficiency [52]. Moreover, providing guidelines for adequate AC utilization and energy subsidies will be helpful for financial burden to economically disadvantaged groups $[12,52]$

\section{Conclusion}

This study identified neighborhoods and vulnerable groups that lack access to residential cooling systems in Florida. We also contributed to gaps in the existing research on AC prevalence by applying recent real estate data on AC ownership, analyzing data at the scale of census tracts, and utilizing spatial regression analysis. We found variability in AC prevalence by urbanicity and sociodemographic characteristics. Based on our findings, we discuss the potential benefits of gathering nationwide AC ownership data and recommend heat prevention measures for vulnerable groups, such as providing LIHEAP, distributing AC units, and installing cooling centers.

\section{Abbreviations}

AC: Air conditioning

AHS: American Housing Survey

HZ: Health Zone

LISA : Local Indicators of Spatial Association

LIHEAP: Low Income Home Energy Assistance Program

\section{Declarations}

\section{Acknowledgment}

We want to acknowledge Estated for providing the real estate dataset that we used for research purposes.

\section{Ethical Approval and Consent to participate}

Not applicable

\section{Consent for publication}


I confirm that I understand International Journal of Health Geographics is an open access journal that levies an article processing charge per articles accepted for publication. By submitting my article I agree to pay this charge in full if my article is accepted for publication.

\section{Availability of data and materials}

The property data was provided from real estate company 'Estated' for research purposes Estated [36]. Archived 1970s census data was accessed from IPUMS NHGIS [35] and contemporary census data was gathered through United States Census Bureau Application programming interface (API) in R [53]

\section{Competing interests}

Not applicable

\section{Funding}

This study was partially supported by a grant from the Centers for Disease Control and Prevention's Climate-Ready States and Cities Initiative (U38EH000942) and NASA Health and Air Quality Applied Science Team (80NSSC21K0430).

\section{Authors' contributions}

YJA and CU designed and wrote the main manuscript. YJA performed the statistical analysis and programming. SW developed the limited areas of figures and discussion. EP and TH contributed to discussion. All authors read, critically revised the paper, and approved the final manuscript.

\section{References}

1. Dahl K, Spanger-Siegfried E, Licker R, Caldas A, Abatzoglou J, Mailloux N, et al. Killer Heat in the United States. 2019.

2. Nayak SG, Lin S, Sheridan SC, Lu Y, Graber N, Primeau M, et al. Surveying Local Health Departments and County Emergency Management Offices on Cooling Centers as a Heat Adaptation Resource in New York State. J Community Health. 2017;42:43-50. doi:10.1007/s10900-016-0224-4.

3. Kuras ER, Richardson MB, Calkins MM, Ebi KL, Hess JJ, Kintziger KW, et al. Opportunities and challenges for personal heat exposure research. Environ Health Perspect. 2017;125.

4. Ziegler TB, Coombe CM, Rowe ZE, Clark SJ, Gronlund CJ, Lee M, et al. Shifting from "community-placed" to "community-based" research to advance health equity: A case study of the heatwaves, housing, and health: Increasing climate resiliency in Detroit (HHH) partnership. Int J Environ Res Public Health. 2019;16:1-19.

5. Gabbe CJ, Pierce G. Extreme Heat Vulnerability of Subsidized Housing Residents in California. Hous Policy Debate. 2020;30:843-60. doi:10.1080/10511482.2020.1768574.

6. Madrigano J, Ito K, Johnson S, Kinney PL, Matte T. A case-only study of vulnerability to heat wave-related mortality in New York City (2000-2011). Environ Health Perspect. 2015;123:672-8.

7. Knowlton K, Lynn B, Goldberg RA, Rosenzweig C, Hogrefe C, Rosenthal JK, et al. Projecting Heat-Related Mortality Impacts Under a Changing Climate in the New York City Region. Am J Public Health. 2007;97. doi:10.2105/AJPH.2006.102947.

8. Matte TD, Lane K, Ito K. Excess Mortality Attributable to Extreme Heat in New York City, 1997-2013. Heal Secur. 2016;14:64-70. doi:10.1089/hs.2015.0059.

9. Bock J, Srivastava P, Jessel S, Klopp JM, Parks RM. Compounding Risks Caused by Heat Exposure and COVID-19 in New York City: A Review of Policies, Tools, and Pilot Survey Results. J Extrem Events. 2021;:2150015. doi:10.1142/S2345737621500159.

10. Fouillet A, Rey G, Laurent F, Pavillon G, Bellec S, Guihenneuc-Jouyaux C, et al. Excess mortality related to the August 2003 heat wave in France. Int Arch Occup Environ Health. 2006;80:16-24.

11. Uejio CK, Tamerius JD, Vredenburg J, Asaeda G, Isaacs DA, Braun J, et al. Summer indoor heat exposure and respiratory and cardiovascular distress calls in New York City, NY, U.S. Indoor Air. 2016;26:594-604. doi:10.1111/ina.12227.

12. Loughnan M, Carroll M, Tapper NJ. The relationship between housing and heat wave resilience in older people. Int J Biometeorol. 2015;59:1291-8.

13. Waugh DW, He Z, Zaitchik B, Peng RD, Diette GB, Hansel NN, et al. Indoor heat exposure in Baltimore: does outdoor temperature matter? Int J Biometeorol. 2021;65:479-88. doi:10.1007/s00484-020-02036-2.

14. Quinn A, TameriusB JD, Perzanowski M, Jacobson JS, Goldstein I, Acosta L, et al. Predicting Indoor Heat Exposure Risk during Extreme Heat Events. Bone. 2014;23:1-7. doi:10.1016/j.scitotenv.2014.05.039.Predicting.

15. Quinn A, Kinney P, Shaman J. Predictors of summertime heat index levels in New York City apartments. Indoor Air. 2017;27:840-51. doi:10.1111/ina.12367.

16. Semenza JC, Rubin CH, Falter KH, Selanikio JD, Flanders WD, Howe HL, et al. Heat-Related Deaths during the July 1995 Heat Wave in Chicago. N Engl J Med. 1996;335:84-90. doi:10.1056/NEJM199607113350203. 
17. Ostro B, Rauch S, Green R, Malig B, Basu R. The effects of temperature and use of air conditioning on hospitalizations. Am J Epidemiol. 2010;172:105361.

18. Cardoza JE, Gronlund CJ, Schott J, Ziegler T, Stone B, O'Neill MS. Heat-Related Illness Is Associated with Lack of Air Conditioning and Pre-Existing Health Problems in Detroit, Michigan, USA: A Community-Based Participatory Co-Analysis of Survey Data. Int J Environ Res Public Health. 2020;17:5704. doi:10.3390/ijerph17165704.

19. O’Neill MS, Zanobetti A, Schwartz J. Disparities by race in heat-related mortality in four US cities: The role of air conditioning prevalence. J Urban Heal. 2005;82:191-7.

20. Reid CE, O'Neill MS, Gronlund CJ, Brines SJ, Brown DG, Diez-Roux A V., et al. Mapping community determinants of heat vulnerability. Environ Health Perspect. 2009;117:1730-6.

21. Nayak SG, Shrestha S, Kinney PL, Ross Z, Sheridan SC, Pantea Cl, et al. Development of a heat vulnerability index for New York State. Public Health. 2018;161:127-37. doi:10.1016/j.puhe.2017.09.006.

22. Uejio CK, Wilhelmi O V., Golden JS, Mills DM, Gulino SP, Samenow JP. Intra-urban societal vulnerability to extreme heat: The role of heat exposure and the built environment, socioeconomics, and neighborhood stability. Heal Place. 2011;17:498-507. doi:10.1016/j.healthplace.2010.12.005.

23. Gronlund C, Berrocal V. Modeling and comparing central and room air conditioning ownership and cold-season in-home thermal comfort using the American Housing Survey. J Expo Sci Environ Epidemiol. 2020;30:814-23. doi:10.1016/j.physbeh.2017.03.040.

24. Kalkstein LS, Nichols MC, David Barthel C, Scott Greene J. A new spatial synoptic classification: Application to air-mass analysis. Int J Climatol. 1996;16:983-1004.

25. Baniassadi A, Sailor DJ, Scott Krayenhoff E, Broadbent AM, Georgescu M. Passive survivability of buildings under changing urban climates across eight US cities. Environ Res Lett. 2019;14.

26. New York Times. When Jacksonville Became the Gateway to Florida. 1969. https://timesmachine.nytimes.com/timesmachine/1969/03/02/90058212.html?pageNumber=574. Accessed 26 Oct 2021.

27. Wang R, Larsen, K, Ray A. Rethinking Locational Outcomes for Housing Choice Vouchers: A Case Study in Duval County, Florida. Hous Policy Debate. 2015;25:715-38. doi:10.1080/10511482.2014.968182.

28. Shorstein A, Baynard C, Kowalski J, Hanson K, Gupta S, Pitel S. A Health Impact Assessment of Subsidized Housing in Duval County, Florida. 2017. http://hpcnef.org/wp-content/uploads/2016/02/Housing-HIA-Report_Final-6-7-17.pdf.

29. Biddle J. Explaining the spread of residential air conditioning, 1955-1980. Explor Econ Hist. 2008;45:402-23.

30. Barcus HR. Heterogeneity of rural housing markets. Rural Housing, Exurbanization, Amenity-Driven Dev Contrasting "Haves” "Have Nots." 2016 ;:51-73.

31. Vant-Hull B, Ramamurthy P, Havlik B, Jusino C, Corbin-Mark C, Schuerman M, et al. The harlem heat project A unique media-community collaboration to study indoor heat waves. Bull Am Meteorol Soc. 2018;99:2491-506.

32. Nardone A, Rudolph KE, Morello-Frosch R, Casey JA. Redlines and greenspace: The relationship between historical redlining and 2010 greenspace across the United States. Environ Health Perspect. 2021;129:1-9.

33. Schell CJ, Dyson K, Fuentes TL, Roches S Des, Harris NC, Miller DS, et al. The ecological and evolutionary consequences of systemic racism in urban environments. Science (80-). 2020;369.

34. Hillier AE. Who received loans? Home owners' loan corporation lending and discrimination in philadelphia in the 1930s. J Plan Hist. 2003;2:3-24.

35. IPUMS NHGIS. NHGIS Data Finder. 1970. https://data2.nhgis.org/main. Accessed 30 Dec 2021.

36. Estated. Property Data. 2021. https://estated.com/account/home. Accessed 30 Dec 2021.

37. United States Census Bureau. American Community Survey (ACS). 2019. https://www.census.gov/programs-surveys/acs. Accessed 29 Jun 2020.

38. United States Department of Agriculture (USDA). USDA ERS - Rural-Urban Continuum Codes. 2013. https://www.ers.usda.gov/data-products/rural-urbancontinuum-codes.aspx. Accessed 30 Dec 2021.

39. Anselin L. Local Indicators of Spatial Association-LISA. Geogr Anal. 1995;27:93-115.

40. Moraga P. Geospatial Health Data. Chapman and Hall/CRC; 2019. doi:10.1201/9780429341823.

41. Paynich R, Hill B. Fundamentals of Crime Mapping: Principles and Practice. Jones \& Bartlett Publishers; 2011. https://books.google.com/books?

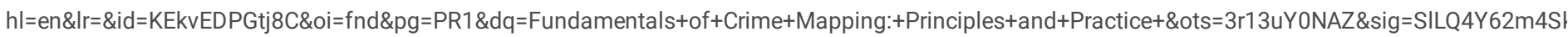
of Crime Mapping\%3A Principles and Practi. Accessed 11 Jul 2021.

42. Elhorst JP. Applied Spatial Econometrics: Raising the Bar. Spat Econ Anal. 2010;5. doi:10.1080/17421770903541772.

43. LeSage J, Pace RK. Introduction to spatial econometrics. 2009.

44. Anselin L, Bera AK, Florax R, Yoon MJ. Simple diagnostic tests for spatial dependence. Reg Sci urban Econ. 1996; 26(1):77-104.

45. LeSage JP. An introduction to spatial econometrics. Rev d'Economie Ind. 2008;123:19-44.

46. Klein Rosenthal J, Kinney PL, Metzger KB. Intra-urban vulnerability to heat-related mortality in New York City, 1997-2006. Heal Place. 2014;30:45-60. doi:10.1016/j.healthplace.2014.07.014.

47. Williams AA, Spengler JD, Catalano P, Allen JG, Cedeno-Laurent JG. Building vulnerability in a changing climate: Indoor temperature exposures and health outcomes in older adults living in public housing during an extreme heat event in cambridge, MA. Int J Environ Res Public Health. $2019 ; 16$.

48. Kovach MM, Konrad CE, Fuhrmann CM. Area-level risk factors for heat-related illness in rural and urban locations across North Carolina, USA. Appl Geogr. 2015;60:175-83. doi:10.1016/j.apgeog.2015.03.012.

49. Schwartz AF. Housing policy in the United States: an introduction. Routledge; 2006.

Page 10/12 
50. Warner, Sam Bass, Tilly C. The Urban Wilderness: a history of the American city. Univ of California Press; 1995. https://fsuflvc.primo.exlibrisgroup.com/discovery/fulldisplay?

docid=alma99383149725106576\&context=L\&vid=01FALSC_FSU:Home\&lang=en\&search_scope=Mylnst_and_Cl\&adaptor=Local Search Engine\&tab=Everything\&query=any,contains, The urban wilderness: A. Accessed 22 Sep 2021.

51. Barreca A, Clay K, Deschenes O, Greenstone M, Shapiro JS. Adapting to Climate Change: The Remarkable Decline in the US Temperature-Mortality Relationship over the Twentieth Century. J Polit Econ. 2016;124:105-59. doi:10.1086/684582.

52. Ito K, Lane K, Olson C. Equitable access to air conditioning: A city health department's perspective on preventing heat-related deaths. Epidemiology. 2018;29:749-52.

53. Kyle Walker, Matt Herman. tidycensus: Load US Census Boundary and Attribute Data as "tidyverse" and 'sf'-Ready Data Frames. 2021. https://walkerdata.com/tidycensus/. Accessed 3 Feb 2022.

\section{Figures}

Figure 1

Study sites (Florida and Duval County with Health Zone)

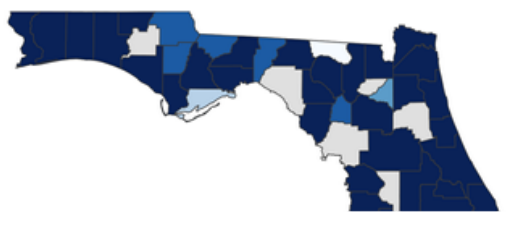

(A)

Percentage of Any AC

75 to 80

80 to 85

85 to 90

90 to 95

95 to 100

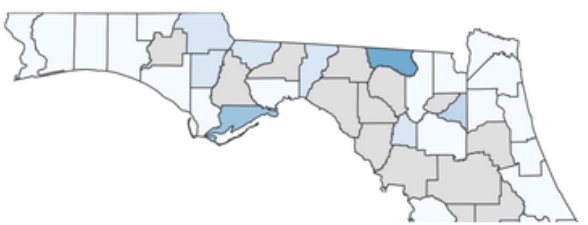

(B)

Percentage of No AC

0 to 5

5 to 10

10 to 15

15 to 20

\section{Figure 2}

Percentage of each AC type in Florida (County level)

Figure 3

LISA maps at the census tract level

Figure 4

LISA map at census tract level in Duval County

\section{Supplementary Files}


This is a list of supplementary files associated with this preprint. Click to download.

- 220201Appendixl.docx

Page 12/12 